\title{
0 pensamento em acção Hannah e Martin no Teatro Aberto
}

Francesca Rayner

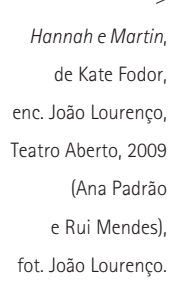

Francesca Rayner é Professora Auxiliar de Teatro e Performance no Departamento de Estudos Ingleses e

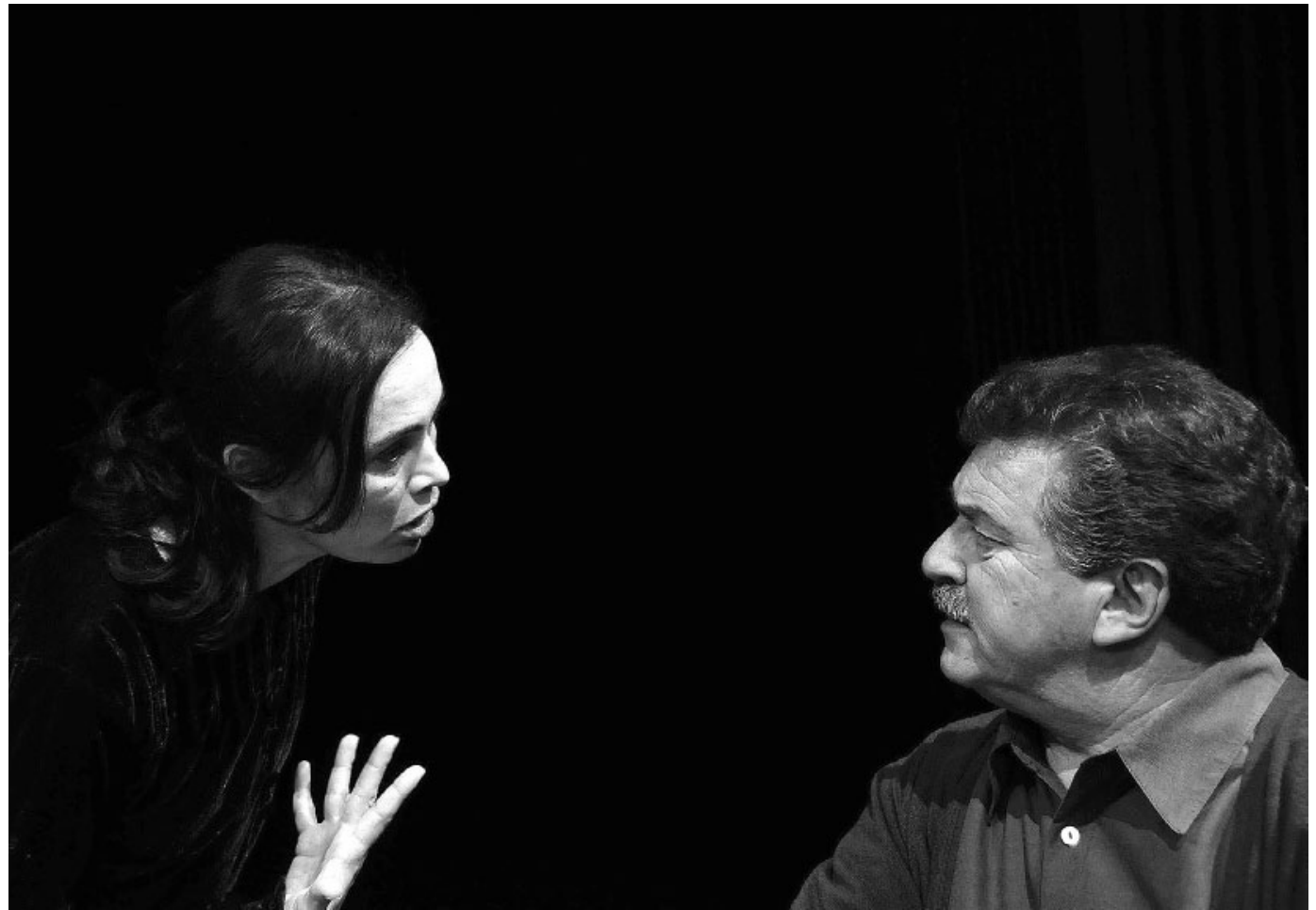

Titulo: Hannah e Martin (2003). Autora: Kate Fodor. Versão: João Lourenço e Vera San Payo de Lemos. Dramaturgia:Vera San Payo de Lemos. Encenação e realização: João Lourenço Cenário: António Casimiro/João Lourenço. Figurinos:Maria Gonzaga. Supervisão audiovisual:Aurélio Vasques. Luz: Melim Teixeira. Interpretação:Ana Padrão, Rui Mendes, Irene Cruz, João Ricardo, Luis Alberto, Cristovão Campos, Maria Ana Bernauer, Cátia Ribeiro, Diogo Mesquita, Francisco Pestana. Local e data de Estreia:Teatro Aberto, 25 de Novembro de 2009.

Peças de teatro sobre ideias correm o risco de criar um teatro estático, na medida em que blocos de monólogo passam a ser ditos por personagens reduzidas a porta-vozes dessas mesmas ideias. Quando as personagens principais do jogo são dois filósofos, existe o risco adicional ou de uma certa inacessibilidade ou da sobre-simplificação das suas ideias. Felizmente, Hannah e Martin resolve com sucesso estes dois potenciais problemas e o resultado é um texto com uma escrita clara e provocadora, encenado com imaginação no palco da Sala Vermelha do Teatro Aberto.

A peça apresenta-nos a relação intelectual e emocional entre Hannah Arendt e o seu antigo professor Martin Heidegger. Este tema, por si só, já seria suficientemente interessante, mas a jovem autora norte-americana, Kate Fodor, que se estreou como dramaturga com esta peça em 2003, estabeleceu o desenrolar desta relação no pesado contexto da Alemanha nazi e do pós-guerra, um período carregado de culpa e recriminação. Enquanto Arendt acaba por compreender as consequências políticas da sua identidade judaica em tal contexto e evolui de uma preocupação com a filosofia teológica para uma nova preocupação com a teoria política, associada a um activismo empenhado, Heidegger, por seu turno, deixase dominar completamente pela "grande ideia" de uma cultura de supremacia alemã e pelo carisma pessoal de Hitler. Embora mais tarde ele reconheça ter sido um erro e insista que o anti-semitismo e a brutalidade de Hitler e das SS representou uma traição dessa grande ideia. A peça questiona se é possivel e eticamente correcto que Arendt perdoe ao ex-professor o seu apoio público aos nazis. No decurso fica claro que as ideias nunca surgem isoladas da história e que as ideias intelectuais expressas na esfera pública têm consequências muito tangiveis $e_{\text {, }}$ até mesmo, fatais. 


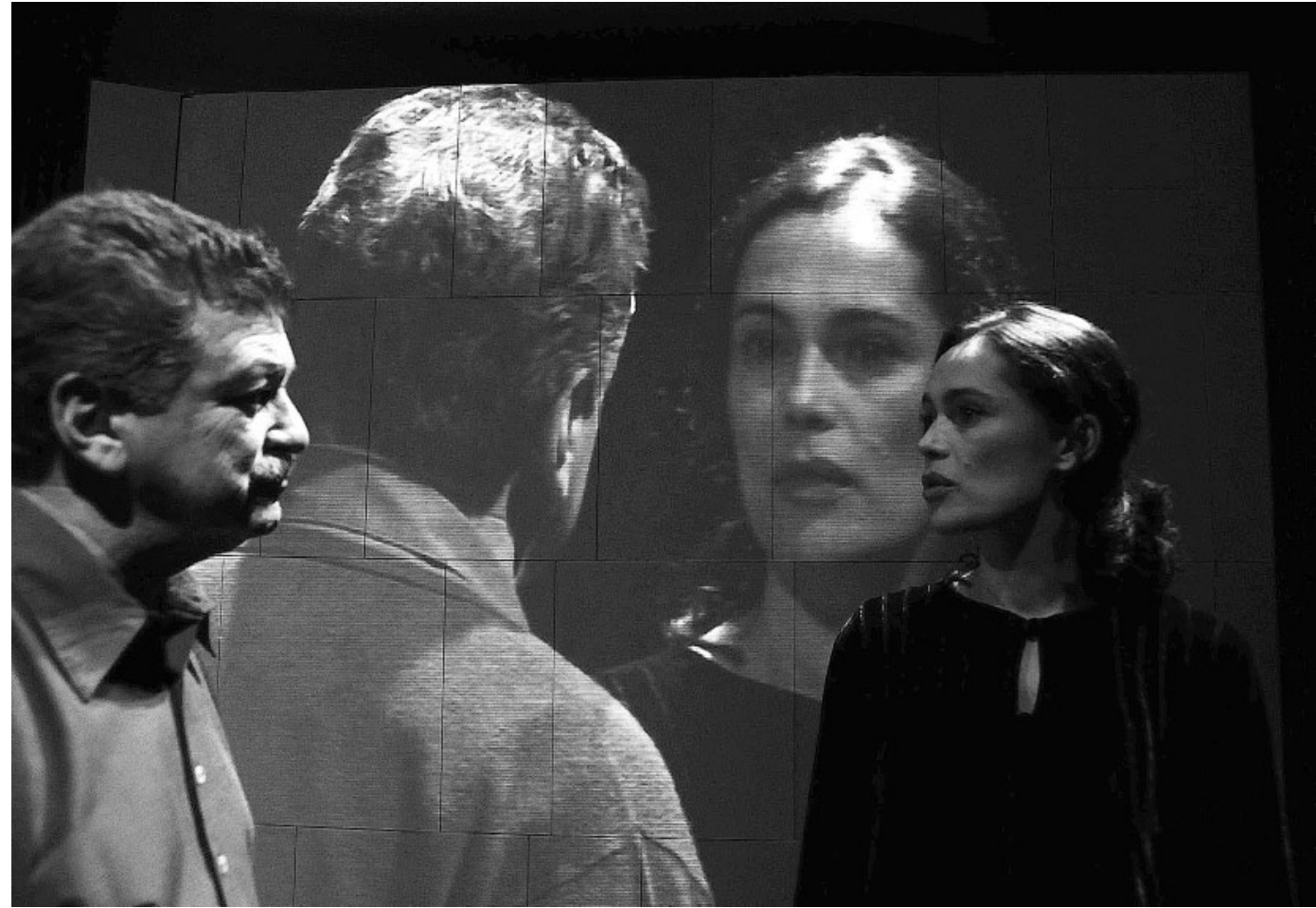

A primeira metade da peça decorre entre dois períodos de tempo, com Arendt (Ana Padrão), exilada nos Estados Unidos, a regressar à Alemanha em 1946 para escrever uma série de artigos para a revista New Yorker sobre o julgamento do líder da Juventude Hitleriana, Baldur von Schirach (papel interpretado em vídeo de forma exemplar por João Ricardo)'. Para Arendt, von Shirach não é, como ele afirma no seu julgamento, menos culpado do que outros por acreditar que estava a educar a juventude alemã para um futuro melhor do que por odiar ou assassinar judeus. As cenas localizadas no passado, no periodo entre 1924 e 1925, tratam do início nervoso da relação amorosa entre Arendt e Heidegger (Rui Mendes) e da influência deste no pensamento inicial dela ${ }^{2}$. Os dois mantêm encontros secretos numa cabana construída para Heidegger pela sua esposa Elfride (Irene Cruz), que pode ou não ter sido a responsável por Heidegger terminar o caso amoroso, quando este envia Arendt para Heidelberg para estudar com o seu próprio mentor, Karl Jaspers (Luís Alberto).

Ao mesmo tempo que as personagens em palco nos explicam toda esta história de viva voz, a narração é contraposta através de projecções - em dois painéis móveis de cada lado do palco - de excertos do julgamento de von Schirach, de imagens documentais do periodo nazi e de gravações em tempo real a preto e branco do que está a acontecer no palco. Essa interacção entre o verbal e 0 visual proporciona uma interpretação altamente eficaz da maneira como estes encontros e eventos aparentemente casuais são, na verdade, momentos históricos ou eventos históricos a caminho de se tornarem história. Como tal, eles ilustram as vastas implicações sociais e políticas dos acontecimentos pessoais que se desenrolam em palco. As projecções proporcionam, também, um foco alternativo de interesse para o público em relação às palavras do texto, permitindo pontos de vista divergentes mas simultâneos dos eventos em palco. 0 único momento em que estas técnicas audiovisuais são menos bem conseguidas é quando Heidegger e Arendt se deslocam para uma zona no fundo do palco que simula o interior da pequena cabana. A transição do diálogo falado para o diálogo gravado não se pode considerar suave e as palavras que dizem um ao outro nem sempre são audiveis para o público.
Hannah e Martin,

de Kate Fodor,

enc. João Lourenço,

Teatro Aberto, 2009

(Rui Mendes

e Ana Padrão),

fot. João Lourenço.

$<$

'Como refere o program da peça, assistimos a um fragmento de liberdade poética, uma vez que Arendt só regressou à Alemanha em 1948 para salvar livros judaicos. Os artigos para a revista The New Yorker foram, na verdade, escritos em 1961 quando Eichmann estava a ser julgado em Jerusalém, acontecimento mais tarde reunido no livro Eichman em Jerusalém. A ideia de que Arendt se esforçou para encontrar justificações para o comportamento de Heidegger é também especulação por parte da dramaturga, embora Arendt vá realmente visitar Heidegger depois da guerra e as questões sobre compreensão e perdão sejam centrais nos seus escritos filosóficos.

${ }^{2}$ No entanto, é

interessante que, nas suas cartas (reproduzidas no programa do espectáculo), Arendt sugira que a sua antiga "inocência" em relação a Heidegger era de certo modo fingida, assumindo que já possuía ideias próprias muito fortes, mas que simplesmente não as conseguia expressar, a menos que coincidissem com as dele. 
No entanto, durante a primeira metade do espectáculo
Hannah e Martin, de Kate Fodor, enc. João Lourenço, Teatro Aberto, 2009

(Ana Padrão e Cristóvão Campos), fot. João Lourenço.

No entanto, quando em 1966 a revista Der Spiege

atacou Heidegger por causa da sua ligação com o nazismo, Jaspers veio em sua defesa publicamente negando que Heidegger tivesse alguma vez deixado de visitar a sua casa por causa de a sua esposa ser

${ }^{4}$ George Steiner, num artigo reproduzido no programa do espectáculo, aceita o facto de a relaçầo

de Heidegger com 0 nazismo ter sido curta

anterior a Hitler ter censura-o por não ter falado publicamente no periodo do pós-guerra argumentando que isso faz dele um cúmplice dos assumido o poder, mas assistimos a alguns momentos maravilhosos, como aquele em que Elfride, a esposa simpatizante nazi de Heidegger chama à parte um rapaz estudante, Günther Stern (Diogo Mesquita), que mais tarde se tornará marido de Hannah e o convida a tornar-se membro do partido nazi por causa da sua extraordinária aparência ariana. À maneira neobrechtiana, são-nos apresentadas duas versões da resposta de Stern. Na primeira, ele reage colérico respondendo a Elfride que, como judeu, nunca consideraria dar tal passo. Em seguida, afastando-se e dirigindo-se a Hannah, mas também implicitamente ao público, ele reformula o acontecido, observando com toda a calma e simplicidade que é judeu. 0 movimento embaraçado de Irene Cruz ao afastar-se dele é nada menos que magnífico.

A segunda parte da peça passa-se no período do pósguerra, com Heidegger já caído em desgraça e proibido de ensinar, em parte como resultado de uma denúncia de Arendt, mas também devido ao seu antigo mentor, Jaspers, ele próprio proibido de ensinar e publicar pelo regime nazi ter alegado que a personalidade autoritária e taciturna de Heidegger prejudicaria os seus alunos ${ }^{3}$. Ao contrário de Jaspers e da sua esposa judia Gertrud (Maria Ana Bernauer) para quem o anterior comportamento público e privado de Heidegger permanece imperdoável, Hannah regressa para visitar o seu antigo professor, na tentativa de compreender as razões de ele ter agido daquela forma e ter mantido silêncio sobre um período tão turbulento da história alemã ${ }^{4}$. Durante o encontro, ela é implacável na crítica severa à ingenuidade e ao desejo de ascensão profissional que o levou a defender um sistema educaciona baseado nos princípios nacional-socialistas; ele, por sua vez, é incapaz de compreender por que razão os outros não são capazes de o perdoar por um erro que ele continua a considerar ter cometido por razões nobres.

Filosoficamente, o afastamento pessoal e político de ambos fica plenamente expresso quando Arendt rejeita o conceito de Heidegger da centralidade da morte para a vida, advogando, em vez disso, a escolha de um caminho individual como característica distintiva de uma vida. No entanto, a peça termina como começou, com Arendt a ditar uma carta à sua aluna, pedindo que Heidegger seja reintegrado e autorizado a publicar livros na Alemanha, uma posição que a aluna, Alice (Cátia Ribeiro), rejeita veementemente, e que contrasta com a própria posição de Arendt em relação a von Schirach, que considerou dever ser enforcado pelas mesmas razões que desculpa em Heidegger.

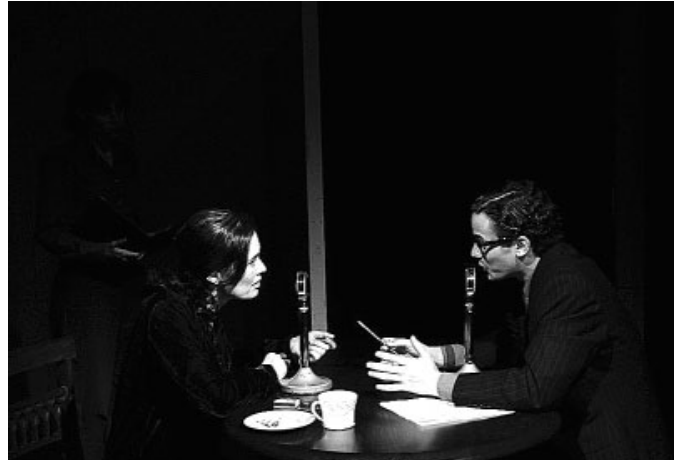

A representação em si, embora inevitavelmente centrada na palavra e nos dois protagonistas, utiliza vídeo, trechos de filmes e gravação em tempo real para contrariar a predominância do texto, e a fluidez da encenação assegura que a sua representação seja feita em movimento rápido. Assistimos também a excelentes desempenhos por parte de actores em papéis secundários, como, por exemplo Irene Cruz, no papel de Elfride Heidegger, Luís Alberto e Ana Maria Bernauer, nos respectivos papéis de Karl Jaspers e Gertrud, e Diogo Mesquita, como o primeiro marido de Hannah. Quanto aos dois protagonistas, Rui Mendes é mais convincente como o destroçado e doente Heidegger da segunda parte da peça do que como o Heidegger carismático e crescentemente reconhecido da primeira, mas Ana Padrão capta de forma soberba as mudanças de Arendt, da ingenuidade à raiva e ao perdão - apesar das alturas em que, temporariamente, se esquece das falas. Os momentos onde ela especula sobre os diferentes motivos que poderiam ter conduzido Heidegger às suas escolhas são habilmente manipulados pela actriz. Crédito sem dúvida, para o encenador João Lourenço, assim como para a adaptação ao teatro de João Lourenço e Vera San Payo de Lemos pela fluência do texto representado e pela forma como a peça é coerente e profunda sem nunca ser pesada. É um prazer ver um espectáculo tão estimulante mas que, apesar disso, deixa um travo amargo na boca. Recorda ao público que, embora possa não ter havido absolutos éticos num período tão complexo e desumano da história, houve, no entanto, consequências concretas para a forma como cada indivíduo, independentemente da sua situação, pôs as suas ideias em prática. Em tal contexto, as palavras são de facto performativas, porque ao serem faladas movem-se imperceptivelmente para se tornarem parte da esfera de acção. 